\title{
LA CONFIGURACIÓN HISTÓRICA DEL MAESTRO PÚBLICO EN COLOMBIA: ENTRE OPRESIÓN Y SUBALTERNIDAD, 1870-2002
}

\section{The historical configuration of public school teachers in Colombia: from oppression to subordination, 1870-2002}

\section{Oscar de Jesús Saldarriaga Vélez* y Claudia María Vargas Aldana**}

Fecha de recepción: 07/10/2014 • Fecha de aceptación: 26/10/2014

Resumen. Este artículo recorre la historia de Colombia, siguiendo las líneas quebradas de la configuración del rol del maestro a través del juego cambiante de tres dimensiones constitutivas de su oficio: sujeto de saber, sujeto público, sujeto de lo social. Juego movido por las fuerzas del poder estatal, el poder pastoral, los partidos políticos y las fuerzas sindicales del magisterio. Sugiere que hubo un cambio de fondo en las luchas por el oficio de maestro: de las reivindicaciones sociales como sujeto genérico de opresión, a las luchas como sujeto específico de saber subalterno.

Palabras clave: Oficio de maestro. Sujeto de saber. Colombia. Movimiento pedagógico. Saber pedagógico. Poder pastoral. Ciencias de la educación. Sindicalismo

Abstract. This article takes a brownian approach to the history of Columbia, tracing the configuration of the structural role played by schoolteachers (the teacher as subject) and in particular the three facets of their profession: as knowledgemakers, as public subjects and as social subjects. In all three instances they are subjected to the impulses of government power, pastoral power, political parties and union forces from within their profession. The article focuses on the fundamental changes in schoolteachers' struggles, which move from the social demands of the oppressed (taken at large) to their struggles as specific, subordinate knowledge-makers.

Key Words: Teaching. Teacher as a knowledge-maker. Colombia. Pedagogical movement. Pedagogical knowledge. Pastoral power. Educational Sciences. Unions.

\footnotetext{
* Pontificia Universidad Javeriana. Facultad de Ciencias Sociales. Departamento de Historia. Cra. 5 No. 39-00 Edificio 95, Piso 3. Bogotá. Colombia. saldarri@javeriana.edu.co

** Secretaría de Educación Distrital. IED Guillermo Cano Isaza. Carrera 16 C \# 62-35 SUR. Bogotá,

D,E.Colombia. claudiamavargas@hotmail.com
}

Cómo citar este artículo: Saldarriaga Vélez, Oscar y Vargas Aldana, Claudia María, «La configuración histórica del maestro público en Colombia: entre opresión y subalternidad, 1870-2002», Historia y Memoria de la Educación, 1 (2015): 287-318. 


\section{ENTRE «LAS URGENCIAS LLORADAS»Y «LA DESPROFESIONALIZACIÓN» DEL MAESTRO}

Que siendo nombrado ha el tiempo de onze años, cinco meses, y sufriendo algunas necesidades para la vida humana, les suplico se sirvan movidos de la caridad del Rey, mandar añadirme algún leve socorro del dicho ramo de Temporalidades para poder subvenir a las urgencias lloradas (Maestro Joseph de Torres, 1787). ${ }^{1}$

Hoy, las circunstancias y las condiciones laborales de los maestros, han cambiado. No me atrevo a decir que sean mejores o peores, pero sí son distintas. Hoy el estado desconoce los méritos que significan "hacer carrera» en esta profesión, ya que no basta con hacer una maestría, un doctorado, una especialización e invertir tiempo, dinero y esfuerzos, para lograr un ascenso. Entre otras cosas, nos hallamos sometidos a una evaluación por «competencias» que desborda nuestras posibilidades al exigir el $80 \%$ de su aprobación como conditio sine qua non para un ascenso. No siendo suficiente este obstáculo, hace 3 años reglamentaron que además de lo anterior, debemos tener 3 años en propiedad para poder aspirar a la mera posibilidad de concurso. De otra parte, nuestro desempeño es evaluado anualmente en las instituciones, y en muchos casos, subordinado al capricho de coordinadores y rectores. De tal suerte que es bastante probable que al finalizar este año lectivo yo tenga que pagar caro esta insolencia. Estas condiciones han redundado en que estos nuevos maestros tengan que guardar silencio frente a los innumerables atropellos que sobre ellos se cometen. A grandes rasgos, esa es la condición de varios de nosotros en el [Colegio Distrital] Guillermo Cano (Profesora Luz Dary González, 2013).²

Dos lenguajes separados por más de doscientos años. El primero, situado en los inicios mismos del oficio de maestro público en el Nuevo Reino de Granada a fines del siglo XVIII, en tiempos de la Ilustración; el otro, el de una joven maestra "de los del 1278», como se ha denominado la actual generación de maestros cobijados por este decreto, el Estatuto de Profesionalización Docente expedido en 2002, frente a aquellos «favorecidos

\footnotetext{
${ }^{1}$ Don Agustín Joseph de Torres y Patiño fue «por muchos años el único maestro público de la capital del Virreinato», y fue el primero en publicar una Cartilla lacónica de las cuatro reglas de Aritmética práctica, en 1797. Alberto Martínez, O. Castro, C.E. Noguera, Maestro, escuela y vida cotidiana en Santafé colonial (Bogotá, Socolpe, 1999).

${ }^{2}$ Luz Dary González Villate, maestra. Carta dirigida al coordinador académico, 20 de agosto de 2013. Documento mimeografiado, cursiva nuestra.
} 
del 2277», los maestros que están aún cobijados por el anterior Decreto de Estatuto docente, vigente desde 1979. ${ }^{3}$

La primera constatación que como historiadores debemos hacer, es que, en este arco de tiempo, que se ha proclamado como la era del progreso y el desarrollo, una injusticia se ha convertido en tradición y un estado de reivindicación se ha hecho crónico para los maestros. Así, se ha sedimentado una memoria política de opresión política y laboral que prácticamente se ha constituido en un rasgo estructural del oficio de maestro; eso que en los asépticos términos de la sociología actual se traduce en una ambigua expresión: «la escasa valoración social de la profesión docente». Pero en esa memoria también residen claves positivas para avanzar a través de las reconfiguraciones contemporáneas del sujeto-maestro. ${ }^{4}$ Los escalafones han afianzado esa condición de subalternidad pasando por alto el estatuto que caracteriza al maestro como productor de conocimientos sobre su práctica, la escuela y su subjetividad. Los efectos de poder desencadenados por un escalafón, su capacidad de definir subjetividades, de ejercer control en los instantes más íntimos de la práctica pedagógica se evidencian en las contradicciones y alianzas que se han formulado alrededor de las relaciones presentes entre los maestros pertenecientes al 2277 y los del 1278 . La comprensión del ejercicio de poder-saber que divide hoy al magisterio colombiano en dos sectores, conlleva la pregunta por los distintos modos de ser que pautaron los diferentes escalafones presentes en el siglo XX. Esbozar algunas pistas históricas sobre esa clave es nuestro propósito en estas páginas.

\footnotetext{
${ }^{3}$ Se ha creado una duplicidad de regímenes entre dos Estatutos (llamados también Escalafones): los maestros «antiguos» («los del 2277») y los «nuevos» («los del 1278»), hasta el punto de que en una misma institución educativa conviven los maestros de ambos Estatutos, junto con los de «nombramiento provisional» (un 20,3\% de la nómina en Bogotá), generando complejos juegos de roces, distancias o alianzas, por la diferencia de condiciones laborales. Colombia, Decreto-Ley 1278 de junio 9 de 2002 por el cual se expide el Estatuto de Profesionalización Docente. Descargado de: http://www.mineducacion. gov.co/1621/articles-86102_archivo_pdf.pdf. Y Colombia-Ministerio de Educación, Decreto 2277 de 1979 (Septiembre 14). Estatuto Docente. Por el cual se adoptan normas sobre el ejercicio de la profesión docente: http://www.mineducacion.gov.co/1621/articles-103879_archivo_pdf.pdf (consultados el 10-04-2014).

${ }^{4}$ Nos inspiramos en la conceptualización propuesta por Olga Lucía Zuluaga, Pedagogía e Historia. La historicidad de la Pedagogía. La enseñanza, un objeto de saber (Bogotá: Siglo del Hombre/Universidad de Antioquia, ([1987] 1999). Cuando se enuncia al sujeto-maestro nos referimos a un concepto teórico, un rol estructural, mientras que, cuando hablamos de las maestras y maestros, o el magisterio, estamos hablando de las personas, individuos o colectivos, existentes históricamente. La idea es que a través de las vicisitudes y luchas históricas se van reelaborando las dimensiones estructurales del sujeto-maestro, como sujeto de saber, como sujeto público y como sujeto social. Ver Claudia Vargas Aldana, La configuración del maestro como sujeto político, social y de saber. Bogotá 1945-1957 (Tesis de Maestría, Pontificia Universidad Javeriana, 2014), 14.
} 
Por ello, una segunda constatación se hace necesaria: muchas cosas han cambiado profundamente en el lenguaje de las quejas. Mientras las palabras del maestro del período colonial brotan mendicantes, barrocas y grandilocuentes, en medio de una dependencia paternalista respecto de las autoridades públicas, la voz de la maestra contemporánea revela una experiencia de resistencia, organización e institucionalización, conflictivas sí, pero sólidas: una carrera docente proveída por el Estado, pero objeto permanente de las luchas magisteriales, ${ }^{5}$ presencia de una organización sindical, y con ella, una conciencia de autonomía profesional en medio de la precarización constante.

Sin embargo, otras fisuras más sutiles se hacen visibles a través de las palabras de la maestra de hoy. La principal, el rechazo al sistema de evaluación permanente para ingresos y ascensos que el decreto 1278 consolida como espina dorsal de la carrera docente, proceso que durante todo el siglo $\mathrm{XX}$ el Estado había tratado - con precario éxito- de asociar a la constitución de un Escalafón Docente, siendo memorables dos hitos: los exámenes realizados en 1936 como condición de formalización del primer escalafón magisterial impulsado por las reformas educativas liberales, ${ }^{6}$ y un segundo examen efectuado en 1999 bajo un gobierno conservador. Evaluaciones a las que el magisterio organizado se ha resistido con todas sus fuerzas, frente a los argumentos estatales sobre la necesidad de tecnificar los mecanismos de ingreso y ascenso en el escalafón y mejorar la gestión de la calidad, combatiendo de paso el endémico mal de la política pública colombiana, el clientelismo. La implantación de la evaluación docente ha sacado a relucir todas las tensiones del sistema educativo, en lo pedagógico, lo político, lo administrativo, y lo financiero, alrededor de estos instrumentos normativos de «regulación del ejercicio docente». ${ }^{7}$ Desde el punto de vista de la Federación que reúne todos los sindicatos magisteriales de Colombia, Fecode, la evaluación actual sería «una medida impuesta por agencias multilaterales, que atenta contra la autonomía de los docentes, con carácter exclusivamente punitivo y que

\footnotetext{
${ }^{5}$ Alexis Pinilla Díaz, «El magisterio y la movilización social en el contexto educativo a principios del siglo XXI», Historia y Sociedad, 18 (Medellín, Colombia), (2010): 107-128. Su información se basa en la suministrada por el OLPED (Observatorio Latinoamericano de Políticas Educativas) en el proyecto Conflictividad Educativa en América Latina iniciado por el Observatorio en 2003.

${ }^{6}$ Jorge Orlando Castro, «La primera evaluación masiva de maestros en Colombia. El examen de revisión de 1936», Pretextos Pedagógicos, 7-8 (1999): 51

${ }^{7}$ Diana M Peñuela, Víctor M Rodríguez, et al., La cuestión docente: Colombia, los estatutos docentes (Buenos Aires: Foro Latinoamericano de Políticas Educativas-FLAPE, 2008), 99-120 (consultado el 1204-2014: http://foro-latino.org/es/publicaciones/la-cuestion-docente-colombia-los-estatutos-docentes).
} 
obedece más a criterios fiscales (hacer más difícil el ascenso en el escalafón) que de calidad», ${ }^{8}$ pero que no evalúa realmente lo pedagógico sino que ata el escalafón docente a la carrera administrativa estatal. ${ }^{9}$

Los maestros del «1278» denuncian que «a la nueva generación de docentes [...] le espera una permanencia condicionada a los resultados de su desempeño dentro del aula y en la institución educativa». ${ }^{10}$ La actual evaluación anual de desempeño, que tiene una parte a cargo de rectores y coordinadores, significa una gestión por los resultados personales de cada maestro, donde se lleva cuenta de variables como «el resultado de sus estudiantes en las pruebas SABER, el número de estudiantes reprobados en la asignatura y el número de estudiantes que desertan de la institución escolar», ${ }^{11}$ dado que también a los rectores los evalúan y se les asignan recursos según los resultados académicos y los «porcentajes de deserción» de su institución, los que igualmente se hacen recaer ahora sobre cada docente. Esto genera, inestabilidad laboral, pues, como el testimonio de la maestra Luz Dary trasluce, se ata a los maestros a una regresiva dependencia personal respecto de sus superiores inmediatos. Las relaciones dentro de las instituciones escolares «empiezan a ser más verticales, dejando atrás el carácter de colegaje entre maestros, coordinadores y rectores», la figura de la «evaluación de desempeño» inhibe la posibilidad de debate académico, atando las decisiones y proyectos a tecnicismos administrativos y a la voluntad de rectores y coordinadores «fortalecida por el miedo constante de la represalia». ${ }^{12}$ Esta ha sido, además, una de las mayores fuentes de división entre los maestros «del 1278» y los del «2277», dado que los profesores cubiertos por el estatuto docente del año 1979 no están sujetos a este sistema de evaluación, y los directivos no pueden ejercer —al menos directamente- el control laboral de resultados sobre estos docentes. ${ }^{13}$

\footnotetext{
${ }^{8}$ Rocío Londoño, Javier Sáenz, et al., Perfiles de los docentes del sector público de Bogotá (Bogotá: Secretaría de Educación Distrital/IDEP, 2011), 22

${ }^{9}$ Peñuela et al., La cuestión docente, 44 ss.

${ }_{10}$ Marcela Bautista, «La profesionalización docente en Colombia», Revista Colombiana de Sociología, 32 (2), (2009): 123. Estas atribuciones de los rectores habían sido fijadas, antes del Estatuto, por una Ley de administración financiera, la cuestionada Ley 715 de 2001 (art. 10), por la cual se dictan normas orgánicas en materia de recursos y competencias (consultado el 15-04-2014: http://www.mineducacion. gov.co/1621/article-86098.html).

${ }_{11}$ Vargas, La configuración del maestro, 9.

12 Vargas, La configuración del maestro, 10.

${ }^{13}$ Los compañeros de la maestra Luz Dary relatan que al fin del año, en efecto, el directivo les rebajó puntos a ella y a sus colegas, alegando «que no eran perfectos» (i?). La situación ha creado un clima de rumores y resentimientos infundados entre las dos generaciones; por ejemplo entre «los del 1278»
} 
En segundo lugar, hay otro elemento del Estatuto 1278 que, este sí, reúne a las dos generaciones de maestros en un frente común de rechazo: este decreto legitima lo que se ha venido llamando «la desprofesionalización de la profesión docente», ${ }^{14}$ cuyo síntoma es la admisión al escalafón de profesionales con título universitario diferente al de Licenciado en Educación, es decir, a profesionales sin formación pedagógica. La justificación de esta política de «flexibilización laboral» es discutible — y a quien primero afecta es a la organización sindical- . Pero la noticia no es nueva, el ingreso de profesionales no-docentes al escalafón en Colombia ya era posible desde el «viejo» Estatuto 2277 de 1979 (art. 10) y se mantuvo en la Ley General de Educación (ley 115 de 1994, art. 198).$^{15}$ La literatura sobre los efectos de las transformaciones postmodernas del trabajo sobre la «vieja concepción de profesión» y en particular en «el profesional docente», es ya tan internacional — global — como el fenómeno, y ya se reconoce que la figura de un nuevo profesional "gerencialista, eficiente y exitoso» aplicada al oficio de enseñar, es tan incompatible como nefasta para la figura «romántica» del sujeto-maestro, el sujeto enseñante por vocación y por saber. ${ }^{16}$ Pero en Colombia, la tendencia insinuada desde 1979 ha terminado por ser legitimada en el Estatuto 1278 de 2002, y aún no se terminan de evaluar ni sus «bondades» — ¿rompe rutinas pedagógicas ya instaladas en la escuela? ¿abre las puertas a especialistas mejor formados en ciertas áreas?-; ni sus «defectos» - el mayor de ellos, deslegitimar las instituciones formadores de docentes, volviendo a depreciar el saber pedagógico como un saber más práctico que teórico, sin un campo epistemológico e intelectual propio, pues a pesar de que los discursos oficiales exijan a estos profesionales hacer cursos de pedagogía $(\dot{\imath}$ ?), éstos siguen siendo vistos como una adición de orden

se propagan rumores sobre «los del 2277»: «debido a su desempeño, nosotros tenemos que asumir una evaluación injusta para ascender, mientras, ellos sólo esperan ascender por el paso del tiempo» (conversaciones personales de los autores con maestros; la cursiva es nuestra).

${ }^{14}$ Raúl Infante y Martha Herrera, «Hacia la desprofesionalización del magisterio colombiano. Balance de la política educativa durante la década del noventa», en Formación de maestros, profesión y trabajo docente, comps. Orlando Pulido y Sua Baquero (Bogotá: Universidad Pedagógica Nacional, FLAPE, 2005), 176

15 "Art. 198. PARAGRAFO. «Los establecimientos educativos privados podrán contratar profesionales con título universitario para que dicten cátedras relacionadas con su profesión o especialidad en la educación básica y media, siendo responsabilidad de dichas instituciones la correspondiente preparación pedagógica».

${ }^{16}$ Stephen J. Ball, «Profesionalismo, gerencialismo y performatividad», Revista Educación y Pedagogía, Medellín, Universidad de Antioquia, 15 (37), (2003): 85-104; Alberto Martínez Boom y Alejandro Álvarez Gallego (eds.), Figuras contemporáneas del Maestro en América Latina. (Bogotá: Magisterio, 2010). 
más empírico que intelectual, y son cuatro veces más cortos que los estudios de licenciatura. ${ }^{17}$

Es la gran paradoja del magisterio colombiano actual, porque estos dos dispositivos legales, el decreto 2277 y la Ley 115, fueron resultado negociado de la movilización y la participación magisterial, y sin embargo, no lograron «escapar a los tintes neoliberales», sobre todo tras las sucesivas reformas que sufrieron, en especial por la mencionada Ley 715 de 2001, considerada por el magisterio colombiano como una verdadera contrarreforma educativa que preparó el actual estatuto docente. ${ }^{18}$ Lo irónico es que en los procesos de reconstrucción de la memoria sobre el Estatuto de 1979 y su definición de "profesión docente», había sido considerado como el momento culminante, el logro histórico de la figura estatal del maestro público. El Estatuto Docente de 1979 delinea, de una forma más sólida, la figura jurídica del maestro que en adelante, en su carácter de funcionario estatal, será entendido como «empleado oficial de régimen especial»:19

Artículo 2. PROFESION DOCENTE. Las personas que ejercen la profesión docente se denominan genéricamente educadores. Se entiende por profesión docente el ejercicio de la enseñanza en planteles oficiales y no oficiales de educación en los distintos niveles de que trata este decreto. Igualmente incluye esta definición a los docentes que ejercen funciones de dirección y coordinación de los planteles educativos de supervisión e inspección escolar, de programación y capacitación educativa, de consejería y orientación de educandos, de educación especial, de alfabetización de adultos y demás actividades de educación formal autorizadas por el Ministerio de Educación Nacional en los términos que determine el reglamento ejecutivo. ${ }^{20}$

\footnotetext{
17 «La anterior normatividad pone de manifiesto que el trabajo de formación a este grupo específico de profesionales no licenciados, busca motivarlos a optar por las rutas de formación continua, acordes con sus intereses, para lograr niveles de profundidad y especialización en el conocimiento pedagógico. Sin embargo, es importante precisar que las propuestas de formación deben, fundamentalmente, articularse a las prácticas como espacios de formación que pueden aportar, de manera más clara, las estrategias pedagógicas y didácticas que se ponen en juego en las interacciones pedagógicas, para la construcción del conocimiento escolar y los procesos de formación de los estudiantes». Ministerio de Educación Nacional, Políticas y sistema colombiano de formación y desarrollo profesional docente (Bogotá: M.E.N, 2012), 113 (consultado el 10-04-2014:_http://www.colombiaaprende.edu.co/html/productos/1685/articles-312233_documentobaseop.pdf).

18 Peñuela, La cuestión docente, 54; Orlando Pulido, María Isabel Heredia, C. Angel, Las desigualdades educativas en Colombia (Buenos Aires: FLAPE, 2010), 36.

${ }_{19}$ Peñuela, La cuestión docente, 54.

${ }^{20}$ Decreto 2277, art. 2.
} 
Sin embargo estas apreciaciones, convertidas en lugar común, son contrarias a la manera en que fue considerado el 2277 por las organizaciones sindicales y sus representantes, quienes consideraron el 2277 «como un escalafón rígido, inflexible y jerarquizado» cuya definición de la carrera docente "es etérea y demagógica», pues establece elementos que contribuyen a «una forma de desprofesionalización docente», específicamente en el artículo $5 .{ }^{21}$

El 2277 afirma taxativamente que «sólo podrán ser nombrados para ejercer la docencia en planteles oficiales de educación quienes posean título docente o acrediten estar inscritos en el escalafón nacional docente» $\left(\right.$ art. $\left.5^{\circ}\right)$, y establece la lista de títulos docentes admisibles, desde bachiller pedagógico, peritos, expertos, técnicos, tecnólogo en educación y normalista hasta licenciado postgraduado en educación. Sin embargo, y sin explicitar mucho el asunto, ya estipula (art. $10^{\circ}$ ) que en el escalafón sean admitidos a la $6^{a}$ categoría (sobre 14), es decir, ya casi a mitad de la escala salarial, "profesional(es) con título universitario diferente al de licenciado en ciencias de la educación», con el requisito de sólo un curso de ingreso. El decreto manifiesta aún tanta inseguridad ( ¿o mala conciencia?) en el asunto, que los títulos profesionales no-docentes no son admitidos para acceder a las categorías más altas del escalafón, la $13^{\mathrm{a}}$ y la $14^{\mathrm{a}}{ }^{22}$

Tema aparte - $-\mathrm{y}$ así se presenta en el texto del decreto-, es el parágrafo d) del mismo artículo $5^{\circ}$, que reconoce como título docente el acta de ordenación sacerdotal equivalente a título profesional en teología y filosofía y ciencias religiosas.

De este eco del Concordato firmado con la Santa Sede, nos ocuparemos en la segunda parte de este artículo. Por lo pronto, señalemos que (¿sólo?) desde el Estatuto 1278 de 2002, en la legislación colombiana se omite toda mención particular de reconocimiento docente a todo "profesionalreligioso».

Ahora bien, lo que en términos de la configuración del sujeto-maestro es más fundamental, más devastador, según varios analistas, es el desmonte

\footnotetext{
${ }^{21}$ Víctor Cristancho, «Estatuto Docente 1965-1982», en Proceso educativo y docente en Colombia. (Décadas 50, 60, 70), documento mimeografiado, 25-29, y Adalberto Carvajal, Educadores frente a la ley (Bogotá: Rodríguez Quito Editores, 1985), 287.

${ }^{22}$ Decreto 2277, arts. 5 y 10.
} 
del concepto de que el saber pedagógico es el saber fundante del oficio de maestro. El movimiento magisterial por el reconocimiento del saber pedagógico, que referiremos más adelante, había llevado, desde la década de 1980, hay que recordarlo, a que el Ministerio de Educación estableciera - y sostuviera su vigencia durante trece años-que

los programas académicos en Educación corresponden a un campo de acción cuya disciplina fundante es la pedagogía, incluyendo en ella la didáctica, por cuanto constituye un ámbito de reflexión a partir del cual se genera conocimiento propio que se articula interdisciplinariamente. ${ }^{23}$

Y para que no quede duda de este reconocimiento de la pedagogía como saber teórico-práctico, la ley se compromete incluso con su estatuto epistemológico: uno de los núcleos básicos de los programas de formación de maestros era

la estructura histórica y epistemológica de la pedagogía y sus posibilidades de interdisciplinariedad y de construcción y validación de teorías y modelos, así como las consecuencias formativas de la relación pedagógica (art. 2).

Puede afirmarse que este enunciado constituye uno de los más altos niveles de legitimidad intelectual y reflexividad académica jamás alcanzado en la historia del oficio de maestro en Colombia. Sólo entre 1870 y 1930, con el auge de la pedagogía pestalozziana en sus versiones liberal y católica, la Pedagogía fue reconocida como un compuesto de Ciencia y Arte, pero se trataba de otro tipo de régimen científico, inconmensurable con el actual, diría Kuhn. El reconocimiento de que la Pedagogía tiene un «estructura histórica y epistemológica» ha sido un logro del Movimiento Pedagógico colombiano de la década de 1980, al que nos referiremos enseguida.

La declaración de la Pedagogía como saber fundante, controvertido evento de saber-poder, ha sido no sólo un indicador de las movilizaciones y luchas, sino también de los agrietamientos en el «campo intelectual de

\footnotetext{
${ }^{23}$ Fórmula reiterada literalmente en tres documentos legales: M.E.N., Decreto 3012 de 1997, por el cual se adoptan disposiciones para la organización y el funcionamiento de las Escuelas Normales (art. 2-f), Decreto 0272 de 1998, por el cual se establecen los requisitos de creación y funcionamiento de los programas académicos de pregrado y posgrado en Educación (art. 2), y Resolución 1036 de abril de 2004, por la cual se definen las características específicas de calidad para los programas de pregrado y especialización en Educación (art. 2).
} 
la educación». ${ }^{24}$ Mientras se establecía así, por decreto, la centralidad del saber pedagógico, otro decreto, el ya referido Estatuto 1278 de 2002, estipulaba que ya no sería requisito exclusivo cursar estudios de Licenciatura para ser maestro de primaria y secundaria. El 1278 no sólo mantiene el criterio de flexibilización laboral respecto de los no-licenciados, sino que, se ha señalado, al cambiar la noción de «profesión docente» por la de «función docente», legitima un verdadero proceso de reconfiguración de la figura clásica del sujeto-maestro como profesional de la enseñanza. ${ }^{25}$ La nueva noción jurídica de "función docente» enumera una serie de actividades, desde la enseñanza, hasta la administración y el acompañamiento a la comunidad, padres de familia, pero no la asigna como antes, a un profesional docente y a un saber con horizonte epistemológico, sino a cualquier profesión que ejerza «directamente procesos sistemáticos de enseñanza-aprendizaje», de donde ya se ha excluido la investigación y la producción de conocimiento:

ARTícUlO 3. Profesionales de la Educación. Son profesionales de la educación las personas que poseen título profesional de licenciado en educación expedido por una institución de educación superior; los profesionales con título diferente, legalmente habilitados para ejercer la función docente de acuerdo con lo dispuesto en este decreto,26 y los normalistas superiores.

ARTÍ́CULO 4. Función docente. La función docente es aquella de carácter profesional que implica la realización directa de los procesos sistemáticos de enseñanza-aprendizaje, lo cual incluye el diagnóstico, la planificación, la ejecución y la evaluación de los mismos procesos y sus resultados, y de otras actividades educativas dentro del marco del proyecto educativo institucional de los establecimientos educativos.

La función docente, además de la asignación académica, comprende también las actividades curriculares no lectivas, el servicio de

\footnotetext{
${ }^{24}$ Mario Díaz, El campo intelectual de la educación en Colombia (Cali: Univalle, 1993); O. Zuluaga y A. Echeverri, «Campo intelectual de la Educación, y Campo Pedagógico: posibilidades, complementos y diferencias», en Pedagogía y Epistemología, O. Zuluaga, et al. (Bogotá: Magisterio, 2003), 11.

${ }_{25}$ Peñuela, La cuestión docente, 45; Una visión sintética y aguda del problema en: Jorge Orlando Castro et al., «De la profesión a la función docente: Una mirada a la formación de los maestros desde los estatutos 2277 de 1979 y 1278 de 2002», Cuadernos de Psicopedagogía, 5 (2008): 60.

${ }^{26}$ Colombia. Decreto-Ley 1278 de 2002: «Art. 12, Parágrafo 1. Los profesionales con título diferente al de licenciado en educación, deben acreditar, al término del período de prueba, que cursan o han terminado un postgrado en educación, o que han realizado un programa de pedagogía bajo la responsabilidad de una institución de educación superior, de acuerdo con la reglamentación que al respecto expida el Gobierno Nacional».
} 
orientación estudiantil, la atención a la comunidad, en especial de los padres de familia de los educandos; las actividades de actualización y perfeccionamiento pedagógico; las actividades de planeación y evaluación institucional; otras actividades formativas, culturales y deportivas, contempladas en el proyecto educativo institucional; y las actividades de dirección, planeación, coordinación, evaluación, administración y programación relacionadas directamente con el proceso educativo.

Las personas que ejercen la función docente se denominan genéricamente educadores, y son docentes y directivos docentes. ${ }^{27}$

Como lo han señalado algunos analistas, el 1278 hace un desplazamiento significativo sobre el modo de concebir el oficio de maestro. Introduce, al lado de la noción clásica de profesión, una nueva noción, la de función docente: «el nuevo estatuto traduce y materializa el modelo de gestión [empresarial], poniendo en primer plano no tanto las condiciones del sujeto como su capacidad (competencia), evidenciada en su desempeño y corroborada tanto por los resultados de sus alumnos y de él mismo a través de los mecanismos de evaluación y seguimiento dispuestos al efecto». ${ }^{28}$

Tras disolver la profesión docente en «funciones», llama poderosamente la atención que el mismo estatuto recurra a un tema que había desaparecido en el Escalafón de 1979, un «marco ético» que vuelve a acudir a una «esencia profesional» y a una "fundamentación moral», una formulación de "principios», que concilia en pocas líneas la diversidad del debate moral colombiano a lo largo del siglo xx, como si en ello no hubieran acaecido luchas políticas, desgarramientos sociales y guerras: el texto legal junta a distancia de comas, la «dignidad humana» del catolicismo, los «derechos del hombre» del liberalismo clásico, "la autonomía», "autodesarrollo», "crecimiento personal» $\mathrm{y}$ «comunicación» del liberalismo avanzado, e incluso «la solidaridad» del socialismo, al igual que recoge un listado de «virtudes morales» personales clásicas (responsabilidad, honestidad, conocimiento, justicia, respeto), agregándoles la versión moderna de la clásica «vocación», el compromiso. Valores a los que se suma una virtud de nuevo cuño empresarial, «la transparencia, todo enmarcado en una «comprensión de la educación como bien público». Helo acá:

\footnotetext{
${ }^{27}$ Colombia. Decreto-Ley 1278, arts. 3 y 4.

${ }^{28}$ Castro et al., «De la profesión», 57
} 
ARTICULO 39. Principios y valores que fundamentan la profesión docente y el quehacer del educador.

La profesión docente tiene su fundamento en el reconocimiento de la dignidad de todo ser humano y sus derechos fundamentales, en el autodesarrollo, en la autonomía, en la comunicación y la solidaridad. Y su regulación debe explicitar y facilitar la práctica de sus valores propios, destacando por lo menos la responsabilidad, la honestidad, el conocimiento, la justicia, el respeto y la transparencia.

ARTÍCULO 40. Marco ético de la profesión docente. El ejercicio de la docencia tiene como fundamento la comprensión de la educación como bien público, como actividad centrada en los estudiantes y al servicio de la nación y de la sociedad. La profesión docente implica una práctica que requiere idoneidad académica y moral, posibilita el desarrollo y crecimiento personal y social del educador y del educando y requiere compromiso con los diversos contextos socio-culturales en los cuales se realiza. ${ }^{29}$

Por un lado, no debe perderse de vista la ambigüedad estructural sobre el carácter público de la educación que ha quedado estatuida en el artículo 67 de la Constitución nacional vigente desde 1991: «la educación es [...] un derecho de la persona y un servicio público que tiene una función social»: la educación se afirma como derecho adquirido, pero personal; la educación se establece como servicio - abierto al sector privado- pero se hace público por una «función social». ${ }^{30}$ Por otro lado, en cuanto a la configuración del sujeto-maestro, éste vuelve a enunciarse como sujeto "con idoneidad académica» (pero no como productor de saber), a la vez que como sujeto público con «idoneidad moral», declarada a partir de "principios y valores»: un rol del sujeto maestro que había desaparecido de las regulaciones en el Estatuto 2277 de 1979, donde la única alusión a lo «moral» era la tipificación de un número de «causales de mala conducta»:

a) La asistencia habitual al sitio de trabajo en estado de embriaguez o la toxicomanía;

b) El homosexualismo o la práctica de aberraciones sexuales;

c) La malversación de fondos y bienes escolares o cooperativas;

\footnotetext{
${ }^{29}$ Colombia. Decreto-Ley 1278 de 2002. Arts. 39 y 40

${ }^{30}$ República de Colombia, Constitución Política de Colombia (1991) (consultado el 18-05-2014: http:// www.constitucioncolombia.com/titulo-2/capitulo-2). Ver María Isabel Heredia, Saberes técnicos y saberes políticos sobre la educación en Colombia, 1978-1994 (Tesis de Maestría. Pontificia Universidad Javeriana, 2012), 220.
} 
d) El tráfico con calificaciones, certificados de estudio, de trabajo o documentos públicos;

e) La aplicación de castigos denigrantes o físicos a los educandos;

f) El incumplimiento sistemático de los deberes y la violación reiterada de las prohibiciones;

g) El ser condenado por delito o delitos dolosos;

h) El uso de documentos o informaciones falsas para inscripción o ascenso en el escalafón, o para obtener nombramientos, traslados, licencias o comisiones;

i) El abandono del cargo;

j) La utilización de la cátedra para hacer proselitismo político. ${ }^{31}$

Ya la misma Constitución del 91 asentaba que «la enseñanza estará a cargo de personas de reconocida idoneidad ética y pedagógica» (art. 68). Pero el Decreto-Ley 1278, además del «marco ético» citado, también tipifica otro número de «Prohibiciones», que aunque análogas a las del 2277, tienen un aire más jurídico-penal, aunque su lenguaje sea más «políticamente correcto». ${ }^{32}$ Por señalar dos elementos notables, ya no se penaliza directamente el homosexualismo, sino que se habla de "conductas que atenten contra la libertad y el pudor sexual de los educandos». Asimismo, se ha incluido la interdicción de "proselitismo religioso" que no se contemplaba en el estatuto de 1979, época en que la enseñanza religiosa no era obligatoria. ${ }^{33}$

Finalmente, en este recorrido sobre el panorama actual de las regulaciones sobre el oficio de maestro, señalemos que en 2010 se promulgó una nueva Resolución Ministerial, la 544. ${ }^{34}$ En ella desaparece el enunciado sobre «la pedagogía como saber fundante», el «educador» se define, de modo ambivalente, como un "profesional con formación pedagógica que [...] orienta procesos de enseñanza y aprendizaje y guía, acompaña y promueve la formación y el desarrollo de las competencias de sus estudiantes», ${ }^{35}$ y procede

\footnotetext{
${ }^{31}$ Colombia. Decreto 2277, art. 46.

32 Colombia. Decreto-Ley 1278, art. 46.

${ }^{33}$ En diciembre de 2006, el Poder Ejecutivo, liberal, creyó necesario establecer una enseñanza religiosa no confesional (i?) en la educación básica y media (consultado el 19-01-2012: http://www.presidencia. gov.co/prensa_new/decretoslinea/2006/diciembre/19/dec4500191206.pdf).

${ }^{34}$ Ministerio de Educación Nacional, «Resolución 5443 del 30 de junio de 2010, por la cual se definen las características específicas de los programas de formación profesional en educación, en el marco de las condiciones de calidad, y se dictan otras disposiciones» (consultado el 9-06-2014: http://www.mineducacion.gov.co/1621/articles-238090_archivo_pdf_resolucion_5443.pdf).

35 Colombia, Resolución 5443, art. 2.
} 
a enumerar las «competencias básicas» y «las competencias profesionales» que deben caracterizar «su perfil». Entre ellas queda una genérica mención a la «competencia» de "desarrollar actividades de enseñanza y aprendizaje fundamentadas en la articulación de conocimientos, conceptos y procedimientos de los saberes de la disciplina, la didáctica, la historia, la epistemología y la pedagogía», ${ }^{36}$ y más adelante, un artículo que llama vagamente a las instituciones de educación superior a desarrollar políticas de «investigación educativa, pedagógica, y didáctica». ${ }^{37}$ Esto en cuanto a la dimensión del saber. Y en cuanto a la moral, ésta queda enunciada a través del lenguaje de «formulación de competencias». Una de éstas, de «nivel básico», es la de:

Reconocer y valorar la diversidad, los derechos individuales y colectivos. Trabajar en equipo y vivir en sociedad con responsabilidad, estableciendo relaciones humanas pacíficas y objetivas, fundamentadas en la confianza, la ética del cuidado, la empatía, la tolerancia, la solidaridad, y el respeto por los demás. ${ }^{38}$

Y en el «nivel profesional» del docente, la competencia ética sería ya:

Actuar con prudencia y tacto con los estudiantes, reconociéndolos como seres humanos en formación, con intereses, valores, potencialidades y particularidades en sus procesos de aprendizaje, y guiándolos para fomentar en ellos el interés por alcanzar nuevas metas, la curiosidad intelectual, la originalidad, la creatividad, la autonomía y la motivación para seguir aprendiendo a lo largo de la vida. ${ }^{39}$

El «reconocimiento del otro», "la ética del cuidado», forman parte del nuevo lenguaje ético de corte pluralista, dialógico, que se ha incorporado en «las competencias» del maestro, en correlato con la densificación de la subjetividad del estudiante que hoy en día admite la escuela: el estudiante como sujeto culturalmente cargado. Pero de nuevo, estas éticas no-normativas se ven coexistiendo legal y temporalmente con exigencias éticas normativas (principios y valores) de corte católico y con éticas liberales que van de la autonomía hasta el éxito individual. ${ }^{40}$

\footnotetext{
36 Colombia. Resolución 5443, art. 2.

37 Colombia. Resolución 5443, art. 2.

38 Colombia. Resolución 5443, art. 2.

39 Colombia. Resolución 5443, art. 2.

40 Ruth Amanda Cortés, «Prácticas de ciudadanización en la escuela contemporánea. Colombia, 19842004», Pedagogía y Saberes, 38 (2013): 63-69.
} 
Este es el inquietante punto de cruce donde asentamos nuestra interrogación hacia el futuro y hacia el pasado de estos procesos de configuración del sujeto-maestro en Colombia: cómo se ha articulado esta conciliación de discursos «tradicionales», «conservadores», sobre la función «pastoral» del maestro, con los discursos (neo)liberales sobre lo público como un híbrido entre derechos y servicios.

\section{SIGLO XX: SUJETOS DE SABER, SUJETOS SOCIALES, SUJETOS POLÍTICOS...¿O SUJETOS MORALES?}

Hemos rastreado ya en otros trabajos, la compleja situación para el sujeto-maestro, heredada de las luchas políticas entre la Iglesia católica y el Estado (poder espiritual y poder político) a lo largo del siglo XIX. ${ }^{41}$ En pocas líneas, el asunto puede describirse así: entre 1868 y 1886, período de hegemonía liberal radical con un régimen político federal, se despliega una reforma instruccionista que construye la primer configuración fuerte del oficio de maestro público sobre la institucionalidad de las Escuelas Normales, y recuperando sutilmente, frente al sujeto-cura, un perfil de sujeto moral civil, apoyado en un saber específico, la pedagogía pestalozziana, que le apuntalaba un mandato educativo y moral.

El Estado encarga al maestro de construir y guardar el ámbito de la moral pública. Lo que aparece como característico del modo como el radicalismo propuso su reforma educativa en Colombia, es que no buscaba eliminar por principio las funciones pastorales del clero, sino más bien redistribuirlas, a la vez que invocaba una especie de «sacralidad civil». Cierto, la Iglesia católica no podía decir que no se respetaba su fuero sobre las conciencias (que lo aceptaren libremente), y ni siquiera se cuestionaba su rol público de guardiana del mundo doméstico — es decir, el de la autoridad paterna, la institucionalidad matrimonial y la formación ética de la infancia- pero el poder ético otorgado al maestro marcaba una nueva línea divisoria entre lo público y lo privado, esa delicada y vital frontera moral de las sociedades modernas. En lo cotidiano recaería sobre el maestro de escuela ese delicado rol, a través del cual el Estado trazaba un límite, recortaba y recuperaba para sí una parte de las atribuciones pastorales del clero creando otro sujeto con funciones paralelas en la formación de la interioridad de la infancia, pero dotado con un

${ }^{41}$ Oscar Saldarriaga, «La racionalidad del fanatismo: Independencia, secularización y educación en Colombia, siglos XVIII a XX», Historia de la educación, 29, (2010): 82. 
saber técnico propio, la pedagogía, que el cura no poseía necesariamente a menos que lo estudiase en instituciones especializadas, las Escuelas Normales. ${ }^{42}$ Desde el punto de vista de las prácticas de saber, desde esta reforma puede datarse en Colombia el inicio del proceso por el cual el maestro de escuela se vio convertido en la ficha de un ajedrez, de un sutil juego de reducción lenta y casi imperceptible, pero efectiva y cotidiana, de la esfera pastoral del clero. ${ }^{43}$

Pero el viejo juego de poder entre el cura y el maestro - ya conocido en las sociedades de la post-revolución francesa-, aunque en la superficie política parecía poder ser jugado como una confrontación directa entre los «peones» de los dos poderes soberanos clásicos, la Iglesia y el Estado, poder espiritual y poder político por el "control de la escuela», ${ }^{44}$ ello significaría, en términos de historia política, diagnosticar el triunfo o la derrota de uno u otro, derrota o triunfo de la secularidad moderna. Y esto, para el caso colombiano, ya estaría sancionado por la historiografía canónica: es sabido que en 1886 el triunfo de una alianza entre liberales moderados - positivistas spencerianos-y de conservadores - tradicionalistas católicos-desembocó en una Constitución que, si declaró al Estado como neutro - tolerancia de cultos-, proclamó a la religión católica como «la de la Nación», legitimándola como «esencial elemento del orden social», y firmando un Concordato con el Vaticano, que dio el sistema educativo oficial a la administración de la Iglesia católica. Como veremos, la cronología política del siglo xx no habría resultado muy favorable al proyecto liberal: salvo un período de dieciséis años (1930-1946) en el que el liberalismo recuperó la hegemonía del Estado, puede decirse que el país estuvo en manos católico conservadoras, dando lugar a una virulenta polarización bipartidista $-\mathrm{y}$ en gran parte a nombre de la religión - en un dispositivo que ha sido bien caracterizado como «el fratricidio colectivo como fuente de nacionalidad». ${ }^{45} \mathrm{E}$ incluso

\footnotetext{
42 «Es un deber de los directores de escuela hacer los mayores esfuerzos para elevar el sentimiento moral de los niños y jóvenes confiados a su cuidado e instrucción, y para grabar en sus corazones los principios de piedad, justicia, respeto a la verdad, respeto a su país, humanidad y universal benevolencia, tolerancia, sobriedad, industria y frugalidad, pureza, moderación y templanza, y en general todas las virtudes que son el ornamento de la especie humana, y la base sobre la que reposa toda sociedad libre». COLOMBIA (Estados Unidos de, 1863-1886), Decreto Orgánico de la Instrucción Pública Primaria ( $1^{\circ}$ de noviembre de 1870) (Bogotá: Imp. de la Nación, 1870), 21.

43 Saldarriaga, «Racionalidad del fanatismo», 89.

${ }^{44}$ Hago acá eco de la caracterización que hace M. Foucault de las tecnologías de poder pastoral y poder de gobierno político.

${ }^{45}$ Marco Palacios, «Un ensayo sobre el fratricidio colectivo como fuente de nacionalidad», en Museo, memoria y nación (Bogotá: Museo Nacional de Colombia, 2010), 419-454.
} 
durante el período liberal, las diatribas y excomuniones eclesiásticas contra todo lo que sentía como atentatorio contra su derecho divino a educar, se produjeron con mayor frecuencia y acrimonia. En 1946, el ala derechista del partido conservador tomó el poder, y en 1953, un golpe militar patrocinado por los dos partidos y la iglesia, instauró un régimen de «pacificación de la Violencia» que en 1957 fue derrocado para dar paso a un régimen de cooptación bipartidista, acordado por 16 años, el cual proclamó —y logróel cese de la confrontación política por motivos religiosos. Pero en este lapso las luchas armadas bipartidistas se transformaron en guerra de guerrillas y subversión política.

En un marco político tal, ¿cómo evolucionó la cuestión del maestro? Nos faltan aún muchos estudios, y estas notas son un ejercicio de formulación de preguntas e hipótesis para emprender trabajos de amplio horizonte. Lo que queremos retomar acá es una pista que la historia de la práctica pedagógica - es decir, el ocuparnos del proceso histórico de la(s) institución(es), los sujeto(s) y los saber(es) de la pedagogía- nos ha permitido abrir: el conflicto entre las figuras del cura y del maestro puede iluminarse de un nuevo modo si lo leemos, no como una lucha binaria entre el Estado y la Iglesia, sino como un juego en donde un tercer espacio institucional - político y de saber-, el de la Escuela pública moderna, ha constituido un polo de negociación, intercambio, hibridación, ....un tercer territorio de construcción de lo social, como trataremos de mostrar.

La pista procede, justamente, de este episodio fundador que fue la Reforma instruccionista liberal de 1870. Un análisis de la estrategia reformadora mostró que

los Instruccionistas siempre tuvieron claro que este proyecto sólo podía ser credibilizado y legitimado si lograban constituir la Instrucción Pública como un servicio público, como un «tercer espacio» entre lo político y lo religioso, que pudiera garantizar la independencia y equidad del Estado frente a los intereses particulares y corporativos, de un lado el "gamonalismo» político y de otro, el "fanatismo» religioso. Era una reforma social que significaba poder introducir «algo» entre la religión y la política. ${ }^{46}$

Lanzar al maestro como una "punta de lanza» que fuera rompiendo las redes de los viejos poderes locales — párrocos, gamonales liberales y conser-

46 Saldarriaga, «Racionalidad del fanatismo», 87. 
vadores, tinterillos, burócratas y padres de familia refractarios. ${ }^{47}$ Tercer espacio que los propios reformadores nombraban como «interés social, pacto, espíritu público, confianza general», y que a nombre de una tercera fuente de autoridad — que empezaba a aparecer como más alta que la Iglesia y el Estado-, la Sociedad, dotaba a la Instrucción Pública de una misión trascendental, espacio salvador que permitiría superar las divisiones partidistas, haciendo aparecer los intereses políticos y eclesiásticos como intereses particulares frente al interés general de la Sociedad: la educación de las generaciones presentes y futuras. A partir del último tercio del siglo XIX, esta función social de la educación, como ámbito (relativamente) independiente de lo político y lo religioso — de hecho, como regulador de lo político y lo religioso—, será el escenario, campo de batalla al que las fuerzas modernizadoras - conservadoras y liberales - llevarán a la Iglesia católica colombiana, pero también las tensiones constitutivas del proceso de configuración del sujeto-maestro en el siglo XX, quedan desde entonces inscritas en dicho campo, a través de las alternancias políticas que hemos resumido. Hemos osado concluir el análisis del proceso del siglo XIX planteando la siguiente paradoja histórica:

Sabemos que en 1886 retornarían triunfantes las posiciones ultramontanas. [...] Se podría decir, como se ha dicho hasta ahora, que el proyecto de independizar la instrucción pública de lo político y lo religioso a fines del siglo xix en Colombia, fue un fracaso. Pero habría que hilar más delgado: el hecho de haber formado por primera vez un cuerpo de funcionarios e intelectuales del saber pedagógico, y un cuerpo profesional de maestros, sostenidos por un saber y un método especializados, y por una red institucional (las normales y la prensa pedagógica), hicieron avanzar, a pesar de todo, el proceso de secularización y de desplazamiento de la moral religiosa al ámbito privado. Aunque no triunfó la laicización —-hegemonía de una moral civil-, sí quedaron creadas las condiciones para que los curas, a pesar de haber recuperado la hegemonía ético-política, no pudiesen ya más suplantar las funciones, el conocimiento y la esfera de acción propia del maestro: a partir de la reforma educativa de 1870 , si los curas se iban a seguir ocupando de la educación, debieron empezar a mostrar al menos tanta o más competencia en los nuevos métodos pedagógicos que los maestros pestalozzianos formados en las normales. De otro lado, el contenido y la simbólica del discurso moral laico, ciudadano, quedaron encarnados por antonomasia en

47 O. Saldarriaga, J. Sáenz y A. Ospina, Mirar la infancia. Pedagogía, moral y modernidad en Colombia, 1903-1946 (Medellín: Colciencias/Uniandes/UdeAntioquia/Foro Nacional por Colombia, 1997), tomo I, 314. 
la figura del maestro público, así este volviera a enseñar religión. La hegemonía monolítica de la Iglesia católica sobre los saberes se fracturó sin retorno y el maestro y la escuela empezaron a ser, poco a poco, en lo local, el contrapeso laico del dispositivo letrado urbano que antes se apoyaba sólo en la parroquia, el cabildo y la alcaldía. ${ }^{48}$

Autorizados análisis han caracterizado este período de la historia (18801930) como el del «ocaso de la autonomía del maestro".49 Pero, como buena paradoja, esta es una historia a contrapelo, pues a la frágil luz de la constitución de ese "tercer espacio», lo educativo como función social, podremos leer, a través de los estatutos docentes, otros elementos del proceso de configuración del sujeto-maestro en Colombia, a despecho de la monolítica presencia de la Iglesia católica, y de las pugnas entre los partidos liberal y conservador en el sistema de instrucción pública oficial. Los cambios en el saber pedagógico, en las instituciones formadoras de maestros —escuelas normales- y en el estatuto del oficio de maestro no coinciden palmo a palmo con la cronología ni la cartografía de los partidos políticos y la lucha Iglesia-Estado. ${ }^{50}$

A inicios del siglo XX, terminando la cruenta guerra civil llamada «De los mil días», que consolidó el triunfo del partido conservador y el casi arrasamiento de la oposición liberal, se emitió la Ley Orgánica de Instrucción Pública (ley 39 de 1903, y su decreto reglamentario de 1904), ${ }^{51}$ que regirían la Instrucción Pública hasta la década de 1930. La primera sorpresa que nos da la documentación histórica, es que la iniciativa de organización de un sindicato de maestros, se dio en el marco del Primer Congreso Pedagógico Nacional, organizado en 1917 por el Ministerio de Instrucción Pública (por el propio Antonio José Uribe), y fue una propuesta de acuerdo legislativo elaborada por el presbítero Carlos Alberto Lleras Acosta, uno de los impulsores de la Acción Social Católica bajo las directrices de la encíclica Rerum Novarum de León XIII. El estigma de las coloniales urgencias lloradas reaparece —en algún momento se refiere a los maestros como a «seres

\footnotetext{
48 Saldarriaga, «La racionalidad del fanatismo», 101.

49 Jesús Alberto Echeverri y Olga Lucía Zuluaga, «El ocaso de la autonomía del Maestro (1880-1903) Moralizar, enseñar y gobernar», Educación y Cultura, 19 (1986): 29-35.

${ }^{50}$ Ver Javier Sáenz Obregón, «Reformas normalistas de la primera mitad de siglo (1903-1946)», Educación y Pedagogía, 7 (14-15), (1995-1996): 154-169.

${ }^{51}$ Conocida como la «Ley Uribe», por su autor, el influyente diplomático y ministro de Instrucción Antonio José Uribe.
} 
infortunados, que siempre viven con hambre»—, pero el propósito central del acuerdo era crear un sindicato profesional, y hablaba en un tono del todo "moderno», en "defensa del magisterio en el orden intelectual, moral y económico», «defensa de sus derechos conculcados»; prevé recursos para «maestros en receso o en caso de paro» —aunque acá paro parece significar desempleo-, e incluso ya habla en clave de reconocimiento de género:

El Congreso Pedagógico de Colombia, considerando:

$1^{\circ}$. Que los maestros, maestras y profesores aislados no siempre pueden hacer valer su voz ni volver por sus derechos conculcados por las respectivas entidades de las cuales dependen o en favor de los que les están confiados.

$2^{\circ}$. Que el espíritu de asociación en la forma concreta de sindicatos informa hoy para bien de la colectividad todas las clases y gremios sociales en Europa y América.

$3^{\circ}$ Que éste es el único medio práctico para proveer a los fines indicados antes en defensa del magisterio en el orden intelectual, moral y económico,

Acuerda:

$1^{\circ}$. Excítese a todos los maestros y maestras de la República a que entren en el movimiento sindical.

$2^{\circ}$. Se fundarán sindicatos profesionales en la capital de la República, y en todas las capitales de los Departamentos, y se procurará que en ellos se inscriban todos los maestros y maestras en ejercicio o no.

$3^{\circ}$. En cada sindicato funcionará una caja de ahorros debidamente reglamentada para atender a las necesidades de los maestros en receso o los más urgentes en caso de paro.

$4^{\circ}$. Estos sindicatos constituirán una federación sindical con el de la capital de la República, cuyos representantes estarán encargados de gestionar ante las autoridades respectivas, los asuntos relacionados con los intereses del sindicato, de la Federación sindical o de sus afiliados.

$5^{\circ}$. Excítese a los directores y profesores de las facultades, colegios de segunda enseñanza, escuelas normales, etc., a que se sindiquen cuanto antes en igual sentido.

$6^{\circ}$. Antes de disolverse el Congreso Pedagógico, las respectivas Secciones nombrarán delegados que estudien y formen el Reglamento de los sindicatos, de acuerdo con el Presidente del Congreso. ${ }^{52}$

\footnotetext{
52 Carlos A. Lleras Acosta, pbro., "Proyecto de acuerdo sobre sindicatos profesionales de maestros y profesores», en El primer congreso pedagógico nacional de Colombia, su historia y sus principales trabajos, Antonio José Uribe (Bogotá: Imprenta Nacional, 1919), 130.
} 
El flamante Acuerdo se aprobó en el Congreso Pedagógico, pero no pasó de las actas, mientras que otro acuerdo, propuesto allí mismo, sobre escalafón salarial del magisterio, llegó a ser, con leves variaciones, Ordenanza de la Asamblea Departamental de Cundinamarca, aunque varias de sus disposiciones (como la de permanencia de cinco años en cada categoría antes de ascender, o la del precario salario de base de \$32), fueron criticadas como injustas por los Hermanos de las Escuelas Cristianas _lasallistas_, ${ }^{53}$ que por la época del Primer Congreso pedagógico nacional, eran la congregación docente que «daba línea» en Pedagogía, tenía a su cargo la formación oficial de los maestros, publicaba manuales y textos escolares, y regentaba no pocos colegios de secundaria en las capitales de departamentos.

El Primer Congreso Pedagógico fue, como fuese, el primer acto nacional de identidad del magisterio, el mejor de que fue capaz la visión educativa y pedagógica de la hegemonía conservadora. Si es cierto que el sujeto-maestro estaba dependiendo en un todo de la organización eclesial, ello se hacía a costa básicamente de su dimensión de sujeto público, autónomo; pues era definido desde lo pastoral como un «maestro-apóstol». Pero por otra parte el saber pedagógico había logrado un grado mucho mayor de complejidad que en la época pestalozziana liberal, hasta el punto en que algunos maestros ya cuestionaban a fondo el método de las lecciones de cosas y proponían métodos alternos, ya marcados por ciertas ideas de la Escuela Activa.

Por otra parte, el Congreso se basó, como tal vez pocos en la historia colombiana, en la producción escrita de muchos maestros de provincia: se seleccionaron 151 trabajos de entre un gran número producido en las Asambleas Pedagógicas municipales y departamentales, y diez se premiaron nacionalmente y se publicaron. Fue un congreso sobre Pedagogía en un sentidofuerte, que incluyó temas de higiene y medicina escolar, ahorro escolar, gimnasia, escuelas para anormales, restaurantes escolares, financiación y presupuesto, bibliotecas, ciudadanía infantil, moral, castigos, reformas al pensum, eliminación de pizarras, y la delicada inspección escolar..., aunque hay que decir que estos temas fueron distribuidos desde las Direcciones de Educación y los escritos de los maestros se fueron produciendo bajo la modalidad de certámenes sucesivos que los iban seleccionando por nivel ascendente de dificultad. ${ }^{54}$

\footnotetext{
53 «Ensayo sobre administración escolar», Revista pedagógica, 3-11 (1920): 41.

${ }^{54}$ Para un análisis detallado de los debates pedagógicos en este Congreso, ver Sáenz, Mirar la infancia, I, 363-370.
} 
En cuanto a su dimensión social laboral, debe decirse que aunque el proyecto de sindicato no se realizó en los años siguientes, el tema tabú ya quedaba lanzado con todas sus implicaciones, aunque, hay que señalarlo, quedara dependiente de las directrices eclesiásticas, que buscaban construir un sindicalismo moderno, pero confesional, gobernado pastoralmente para tramitar las «urgencias lloradas», temiendo que el magisterio cayera en las redes proselitistas del liberalismo, o peor, del comunismo. El Primer Congreso Pedagógico nacional situó la dimensión pública del maestro en un nivel distinto al de la vigilancia y del control; ${ }^{55}$ esta vez se entendió a los maestros como interlocutores del Estado en la «estrategia oficial de fortalecimiento del oficio de maestro frente a los poderes locales» al tiempo que dejó entrever la «estrategia católica» de organizar al magisterio alrededor de un sindicalismo cristiano a lo León XIII. ${ }^{56}$

Haciendo ahora un giro en la lectura de la conformación del sujeto-maestro en la historia del siglo xx colombiano, seleccionaremos a continuación otros momentos fuertes de la organización política del magisterio, esta vez en clave de la formación de las organizaciones sindicales, primero bajo la estrategia liberal de los años 1934 a 1946, y luego bajo la «recatolización» de la educación desplegada por los gobiernos conservadores derechistas, ${ }^{57}$ hasta la creación de las organizaciones sindicales de oposición. En breves líneas, queremos sostener que la constitución del sujeto-maestro, en su dimensión de sujeto social, sólo pudo lograrse cuando la organización del magisterio se desprendió del rol de instrumento moral y político de los partidos, de la iglesia y finalmente del Estado mismo: de sujeto oprimido a sujeto en condición de subalternidad, esto es, consciente de sus potencias de saber-ciudadanía-reconocimiento.

\footnotetext{
55 Vargas, La configuración del maestro, 124.

56 Sáenz, Mirar la infancia, I, 370

57 Es aún tema de debate la filiación pro-fascista y falangista del dirigente conservador, Laureano Gómez (1898-1965), presidente de la República entre 1950 y 1951, aunque hay un acuerdo en que se trataba de un nacionalismo católico de corte corporativista. Existió un sector de ultra derecha conservadora que se proclamó abiertamente fascista, aunque su peso político fue relativamente minoritario. Ver Hésper Pérez, «Acerca del nacionalismo católico de Laureano Gómez, 1930-1946», Revista Colombiana de Sociología, 20 (2003): 31-40; James Henderson, La modernización en Colombia: los años de Laureano Gómez, 1889-1965 (Medellín: Universidad de Antioquia, 2006); César Ayala, «Trazos y trozos sobre el uso y abuso de la Guerra Civil Española en Colombia», Anuario Colombiano de Historia Social y de la Cultura (2011) (consultado el 26-10-2014: http://www.revistas.unal.edu.co/index.php/achsc/article/view/28086/35982).
} 
Las tensiones entre el Estado, la Iglesia y los partidos políticos heredadas del siglo XIX siguieron alimentándose a lo largo de la primera mitad del siglo XX. Estos polos se disputaron el control de lo educativo, poniendo al maestro en su campo de luchas, como objeto e instrumento de acción. Dicha visibilización del sujeto-maestro lo situó en medio de la pugna de los polos de tensión, desde los cuales se formularon tres mecanismos de subjetivación, encargados de asegurar tanto el sometimiento del maestro como la formación de sus dimensiones. Tres mecanismos de regulación de su oficio generados en el campo pedagógico colombiano: el escalafón docente, los debates sobre su formación pedagógica y el lugar social asignado al maestro en la cultura y en la organización sindical. En el marco de la apropiación de estas "formas de poder», las maestras y maestros encontraron posibilidades de reconfiguración, puesto que la apropiación del poder implica su necesaria transformación, ya sea en sometimiento, ya en posibilidades de existencia del sujeto. ${ }^{58}$ La dinámica de esos tres mecanismos de regulación de su oficio mostraría que las prácticas de poder generaron intersticios que permitieron al sujeto-maestro tomar distancia, recuperar o transformar aspectos de su oficio, de modo que en dicha reconfiguración se posicionara como polo activo de tensión en el campo pedagógico.

De este modo, alrededor del Escalafón Docente se generó una serie de intersticios en los que las maestras y maestros redefinieron los juegos de poder. Primero, en la década de 1930 las maestras y maestros resistieron al Estado como garante de su saber, defendiendo el papel de las Instituciones formadoras de maestros, y ello frente a la figura del cura. Segundo, los espacios de participación en las Juntas de Escalafón, Nacional y Seccionales, permitieron a los representantes de los maestros incidir en decisiones con respecto al ascenso, ingreso y expulsión del escalafón. Tercero, aunque no se conoce la intensidad, el Escalafón fue un baluarte que protegió a algunos maestros liberales de la expulsión y reubicación en zonas rojas durante el período de guerra civil bipartidista conocido como «la Violencia» (1948-1960).

La política liberal de la difusión de la cultura y el desarrollo de la pedagogía activa entre 1942-1953, abrieron para el sujeto-maestro el rol de líder de la comunidad, pues se pusieron en sus manos responsabilidades que iban más allá de la enseñanza de conocimientos: fue entendido como

${ }^{58}$ Judith Butler, Mecanismos psíquicos del poder: teorías sobre la sujeción (Valencia: Universitat de Valencia, 2011), 25. 
el líder intelectual, como el «arquitecto de la patria». Esta politización del maestro y las responsabilidades que cobijaron su dimensión pública y de saber, conllevó a la apropiación de «la alta dignidad de su labor» ya no como instrumento y portavoz de una política estatal o una política de partido, sino que «la alta dignidad personal y pedagógica» la enfocó en su lucha por participar en la definición de lo educativo.

El Estado buscó en dos ocasiones —en 1917 con la Iglesia y el partido conservador, y en 1934 con el partido liberal— la creación de una federación de maestros articulada a su política de creación de un "tercer espacio» para la educación. El gobierno liberal centró su influencia en un sindicato enfocado sólo en la enseñanza secundaria. Durante la presidencia de Eduardo Santos (1938-1942) se afianzó toda una dinámica estatal para establecer el control del Estado sobre los sindicatos, incluyendo los de maestros; en esta línea se desarrolló el sindicalismo magisterial durante los años de la Violencia y del Frente Nacional. Desde la ley $6^{\text {a }}$ de 1945 hasta los gobiernos del Frente Nacional (1958-1974), ${ }^{59}$ hubo un proceso de encauzamiento de los sindicatos independientes hacia los intereses de las clases dirigentes, por parte de los partidos tradicionales:

Cuando se produce la legislación laboral de 1945 ya hay confluencia en los gremios patronales y en los partidos políticos tradicionales en lo fundamental, para limitar la acción del sindicalismo y descarrilar su dinámica independiente. [...] los gobiernos del Frente Nacional van a aplicar unas disposiciones legales convenidas para el manejo de la cuestión social, [...] básicamente hay un desarrollo de continuidad, en el propósito de controlar el sindicalismo y circunscribirlo al ámbito económico y de colaboración de clases. ${ }^{60}$

En Bogotá, hacia 1942, se constituyó ACPES (Asociación Colombiana de Profesores de Secundaria), un sindicato de maestros de secundaria

\footnotetext{
59 Coalición bipartidista que dio fin a «la Violencia», En reacción a la dictadura militar de Rojas Pinilla (1953-1957) y luego de una década de grandes índices de violencia y enfrentamientos políticos radicales, los representantes de ambos partidos, Alberto Lleras Camargo (Partido Liberal) y Laureano Gómez Castro (Partido Conservador), se reunieron para discutir la necesidad de un pacto entre ambos partidos para restaurar la presencia en el poder del Bipartidismo. Se estableció como sistema de gobierno que, durante los siguientes 16 años, el poder presidencial se alternaría, cada cuatro años, entre un representante liberal y uno conservador. Ver Marco Palacios, Entre la Legitimidad y la Violencia. Colombia 1875-1994 (Bogotá: Editorial Norma. 1995), 189-238.

${ }^{60}$ Álvaro Oviedo Hernández, Sindicalismo colombiano. Iglesia e ideario católico 1945-1957 (Quito: Universidad Simón Bolívar, Corporación Nacional, 2009), 196.
} 
promovido por el Estado liberal. Sin embargo, las condiciones laborales, la concepción de apostolado y el bipartidismo frenaron esta iniciativa. La Iglesia a través de la política defensiva de la Acción Católica encontró en el sindicalismo católico un espacio para mantener a maestras y maestros bajo su influjo ideológico y controlar espacios decisivos como las Juntas de Escalafón. Pero, a pesar de la subordinación a la Iglesia y al Estado, estas dos iniciativas fueron legitimando las actividades sindicales como elementos propios de la vida magisterial. ${ }^{61}$

La inestabilidad en las condiciones laborales de los maestros, el clientelismo, los bajos salarios, el poco reconocimiento social de su oficio, las aspiraciones de ascenso social, la concentración en la capital de, las dificultades de los maestros de provincia vía migración rural y su nula participación en la definición de las políticas educativas, tejieron la red de condiciones que contribuyó a la articulación de las maestras y maestros bogotanos en un sindicato nuevo: la Asociación Distrital de Educadores en Bogotá, que participó en una serie de transformaciones en las dimensiones básicas del sujeto-maestro. En cuanto al saber, la producción de pasquines cuya autoría era de los integrantes de los sindicatos, rompió las prácticas que entendían el aula como el único espacio de realización intelectual, el maestro también podía escribir. Igualmente, la dimensión de saber se articuló profundamente con la dimensión pública hasta el punto de ser su sustento, pues la reivindicación del papel de la pedagogía en la transformación de la cultura la habilitó como saber legítimo para discutir y participar en la definición de lo educativo. El maestro como líder intelectual abanderó la defensa de una educación para el pueblo colombiano, capaz de garantizar su desarrollo intelectual y físico, como se ve en la foto de la pancarta que antecede la marcha de las maestras en 1960: «Estamos en huelga de hambre contra el hambre física e intelectual del pueblo colombiano». El maestro se vio a sí mismo como el defensor del niño y la escuela, asumiendo para sí, el logro del mejoramiento de locales escolares, los refrigerios, etc.

\footnotetext{
${ }^{61}$ Adalberto Carvajal, Educadores frente a la ley (Bogotá: Rodríguez Quito Editores, 1985). Adalberto Carvajal fue maestro de escuela, integrante de la ADE y fundador de FECODE. Es autor de libros como Hacia un nuevo enfoque del derecho del trabajo (1978), y Derecho al trabajo y derechos sociales en la nueva Constitución (1991).
} 


\section{MARCHA DE MAESTROS. DÉCADA DE MIL NOVECIENTOS SESENTA}

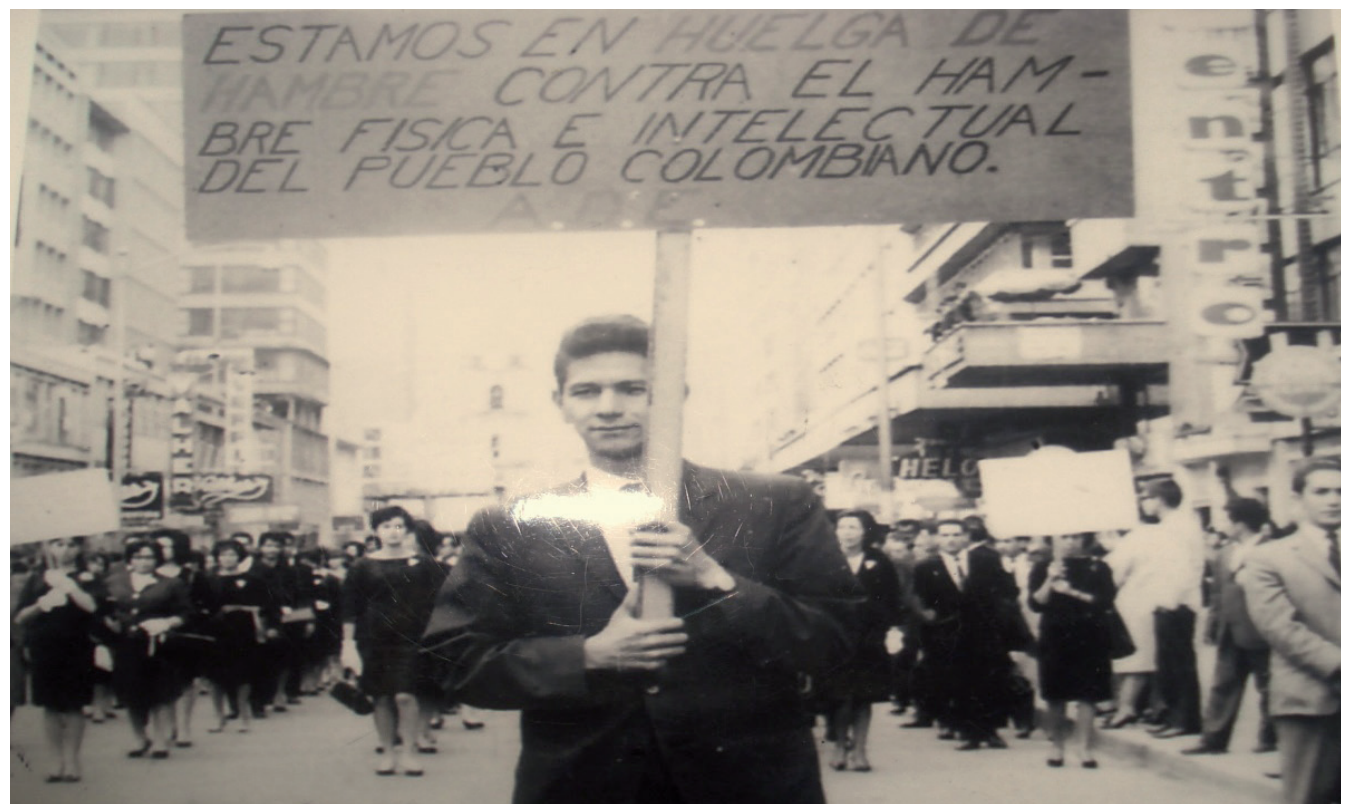

Fuente: Archivo Personal Víctor Cristancho (ADE)

El sindicato de la ADE, junto con maestros de Cundinamarca y del Valle, se articularon alrededor de la Federación Nacional de Educadores (Fecode); así se marcaron dos aspectos fundamentales. La Fecode se desarrolló como un intento de independencia de los maestros y maestras frente a las influencias partidistas, las centrales obreras, y las relaciones patronales con el Estado y la Iglesia, proclamando una separación de la concepción del maestro como Apóstol, expresando dicha ruptura en otro lema de la huelga de 1960, «los maestros no son Apóstoles, sino explotados». ${ }^{62}$ En términos de su dimensión social, las luchas del sindicato, en alianza con Fecode, generaron una ruptura importante con concepciones que ligaban su oficio al sacrificio y a la miseria; de ahí la reacción eclesial. ${ }^{63}$ También permitieron a largo plazo una mayor estabilidad, lo cual se logró bajo la redefinición del Escalafón docente en 1979. Las luchas por el Escalafón, iniciadas por

\footnotetext{
${ }^{62}$ Laureano Coral Quintero, Historia del movimiento sindical del magisterio (Bogotá: Fondo Editorial Suramérica, 1980), 74.

63 «La enseñanza marxista le quitó sentido apostólico al magisterio colombiano», El Siglo [Bogotá], marzo 20 (1950): 1. Ver Vargas, La configuración del maestro, 190.
} 
este sindicato en la década de los sesenta buscaron definir la dimensión pública del maestro bajo el criterio del estímulo y no de la represión. Además, concibió como elemento fundamental de la profesionalización del maestro impedir la entrada de profesionales con «títulos no docentes», defendiendo la pedagogía como elemento sustancial para el ejercicio de la enseñanza. ${ }^{64}$ Sin embargo, como ya se señaló, hasta el estatuto de 1979 el Estado reconocía los títulos eclesiásticos como títulos docentes.

Martínez Boom, Noguera y Castro habían señalado que la condición del maestro como sujeto público bajo el régimen colonial le había marcado una triple opción: «pensar en otro destino, refugiarse en la vocación para sobrellevar las vicisitudes de la enseñanza o interiorizar la ilusión del maestro como intelectual». ${ }^{65}$ Sólo hasta la década de 1960, con la emergencia de los sindicatos se amplían las opciones: esperar los frutos de la lucha organizada e incidir en las políticas educativas. Y aún otra (vieja) opción se renueva en los años recientes con el Movimiento Pedagógico.

\section{EL MOVIMIENTO PEDAGÓGICO COLOMBIANO, UNA CUARTA DIMENSIÓN}

Podemos ya afirmar que como en las tradiciones más clásicas de consolidación de la identidad y el estatuto de los maestros latinoamericanos - las de las luchas sociales de las clases trabajadoras-, en Colombia también se hicieron visibles primero las luchas magisteriales como sujetos laborales-gremiales y como sujetos públicos-políticos, privilegiando las tensiones entre lo laboral y lo profesional, o bien las tensiones por la función política de la enseñanza según el tipo ideal de sociedad a alcanzar. ${ }^{66}$ En países como Argentina o México ya se habían iniciado estas luchas desde finales del siglo XIX, ${ }^{67}$ pero en Colombia, como hemos visto, esta

\footnotetext{
${ }^{64}$ Víctor Cristancho, Proceso educativo y docente en Colombia. (Décadas 50, 60, 70), documento mimeografiado, (Bogotá, s. f.), 2. Cristancho es un maestro miembro del grupo de fundadores de la ADE.

${ }^{65}$ Martínez, Maestro, Escuela y vida, 124.

${ }^{66}$ Sólo un ejemplo de la abundante literatura que ha canonizado esta distinción: A. Loyo, «Los sindicatos docentes en América Latina: entre la lógica laboral y la lógica profesional», Revista Iberoamericana de Educación, 25, (2001): http://www.rieoei.org/rie25a03.htm.

${ }^{67}$ Para esbozar una panorámica latinoamericana, ver en especial, el notable trabajo de FLAPE (Foro Latinoamericano de Políticas Educativas), sobre «la cuestión docente» en Argentina, Chile, Brasil, Colombia, Nicaragua y Perú. Ver su website: http://foro-latino.org/. Destacamos: Graciela Diker y Juan Carlos Serra, La cuestión docente. Argentina: Las políticas de capacitación docente (Buenos Aires: Colección Li-
} 
transformación ha sido sin lugar a dudas un proceso del siglo XX, e incluso casi de la segunda mitad del siglo Xx. Pero en la experiencia colombiana reciente, la dimensión del maestro como sujeto de saber ha emergido como movilización social y como producción investigativa y teórica, modificando de hecho la visión que se ha tenido de las relaciones entre las otras dos dimensiones, dando lugar a un nuevo tipo de luchas, luchas por el saber pedagógico.

En efecto, a partir de la década de los años 1980, en Colombia se ha producido un acontecimiento, convergencia de varios procesos divergentes, que en términos militantes nombraríamos como «la lucha del magisterio por el reconocimiento intelectual de su oficio», en términos analíticos podemos llamar «la reconfiguración de la subjetividad del maestro como productor de saber pedagógico", y en términos políticos nombramos como la transfiguración de su subjetividad política, pasando de autorepresentarse como un «sujeto social oprimido» entre otros, a reconocerse como un trabajador intelectual o de la cultura, que ha sido relegado a la condición de subalternidad intelectual por un régimen (epistemológico-político) de saber. ${ }^{68}$ Más aun, la tesis del carácter instrumental de la pedagogía como saber, y del maestro como «intelectual subalterno», como instrumentador de fines, teorías y procedimientos producidas desde fuera de la escuela, se ha postulado como la causa estructural de la precariedad experimentada por los maestros en sus funciones política y social.

Varios grupos de investigación universitarios nos hemos enganchado en esta batalla, desde distintos frentes: unos contra la relación de la escuela con las ciencias "mayores», otros ante las tecnologías curriculares, otros en el «campo intelectual de la educación», y en fin otros, en el ofi-

bros FLAPE: http://foro-latino.org/es/publicaciones/la-cuestion-docente-argentina-las-politicas-de-capacitacion-docente); Ver también el caso del Movimiento Pedagógico en Chile: Rodrigo Cornejo y Leonora Reyes, La cuestión docente: Chile, experiencias organizacionales y acción colectiva de profesores (Buenos Aires: Fundación Laboratorio de Políticas Públicas, 2008) http://foro-latino.org/es/publicaciones/la-cuestion-docente-chile-experiencias-organizacionales-y-accion-colectiva-de-profesores.

${ }^{68}$ La experiencia chilena del Movimiento Pedagógico entre los años 1987 a 1994 halló una enunciación crítica sobre el maestro-sujeto de saber, aunque su dispositivo formativo fue diferente al colombiano: «Tanto en Chile como en el resto de América Latina, la construcción de una propuesta educativa nunca se constituyó en un eje importante del quehacer de las organizaciones de docentes. Por el contrario, más bien se tendió a considerar "lo pedagógico" como un aspecto neutro, técnico, propio de la formación profesional, sin darle un sentido social y político» (Cornejo, La cuestión docente, 103). La observación es discutible, pero manifiesta las tensiones entre estas tres dimensiones del oficio de maestro. 
cio de maestro y en el saber pedagógico. ${ }^{69}$ Una lucha que se enfrentaba al peso de dos tradiciones teórico-políticas: por un lado, a la tradición institucional nutrida por el pensamiento internacional funcionalista y tecnocrático, ese "evangelio del desarrollo» que nutría a las Ciencias de la Educación (Sociología, Psicología, Economía y Planificación), y a una reforma curricular conocida como «la tecnología educativa», con el objetivo «de impactar en la cultura profesional del maestro», que se evaluaba como empírica y a-científica.

Se enfrentaba, por otro lado, a la tradición académica de las Ciencias Sociales que, aún a nombre del pensamiento crítico, seguían condenando a los profesores a no ser sino los idiotas útiles de la reproducción capitalista, operarios de una institución concebida como pérfido aparato ideológico del Estado burgués y pro-imperialista. Los intelectuales esclarecidos construían discursos de desconfianza y desprecio sobre el oficio y se referían a la pedagogía como «obstáculo epistemológico». Ninguna paradoja mayor que, en las doctrinas que se presentaban como las más libertarias, el maestro fuera condenado sin remedio al más desesperanzador de los lugares.

En ese encuentro entre intelectuales, activistas y maestros, varios autores habían sido utilizados para tratar de escapar a este mecanicismo: Habermas, Gramsci, Bourdieu, Canguilhem, Bernstein, entre otros; pero una pareja de Licenciados $^{70}$ en Filosofía e Historia de la Facultad de Educación de la Universidad de Antioquia formuló una línea de investigación y convocó un grupo interuniversitario bajo el nombre de Historia de la práctica pedagógica en Colombia - GHPP-, apropiándose de la caja de herramientas arqueo-genealógicas de Michel Foucault. Este evento pronto se mostraría como un acontecimiento de saber, pues activó la pregunta por el estatuto intelectual subalterno del maestro y el carácter de saber sujetado (sometido) de la pedagogía. Era un escándalo que unos «licenciados» usaran el sofisticado instrumental analítico sobre las prácticas discursivas y no-discursivas, los sujetos de saber y los regímenes de institucionalización del conocimiento y que formulasen que «la opresión cultural» a la que está sometido el sujeto-maestro procede, estructuralmente, no tanto de

\footnotetext{
${ }^{69}$ Ver Carlo Federici et al., «Límites del cientificismo en Educación», Revista Colombiana de Educación, 14 (1984): 69-90, y la respuesta de Carlos Vasco, «Límites de la crítica al cientifismo en educación», Revista Colombiana de Educación, 16 (1985): 95-114. Las principales posiciones se hallan en Mario Díaz (ed.), Pedagogía, Discurso y Poder (Bogotá: Corprodic, 1988).
}

70 Es el título que se le da en Colombia a los profesores egresados de las Facultades de Educación. 
su origen socioeconómico proletario ni de su alienación a una ideología dominante - en suma, de las dimensiones social y política de su oficio-, sino del régimen de verdad de las ciencias del hombre en donde las Ciencias de la Educación han fijado a la Pedagogía un rol instrumental en la enseñanza de los saberes institucionalizados como científicos. ${ }^{71}$ Pero la singularidad de la coyuntura hizo que estos discursos académicos, críticos pero eruditos, hallaran resonancia y difusión en otro ámbito de la vida de maestras y maestros. En un tercer frente surgía la organización sindical del magisterio, Fecode, que rompiendo con su discurso tradicional reivindicativo del gremio, se propuso enfrentar ideológicamente la reforma oficial y recuperar, para las maestras y maestros, el reconocimiento de su función de "trabajadores de la cultura». ${ }^{72} \mathrm{Al}$ lado del sindicato, florecían también varias ONGs dedicadas a la búsqueda de pedagogías alternativas, populares y críticas. Y como lo declaran las conclusiones del XIII Congreso de Fecode, ya para 1985,

el Movimiento Pedagógico [constituye] una estrategia política y cultural de los maestros colombianos para contribuir a la generación de una conciencia histórica de una nueva escuela para una nueva sociedad. ${ }^{73}$

Uno de sus dirigentes, el «profe» Abel Rodríguez, sintetiza la convergencia de fuerzas:

el Movimiento Pedagógico fue propiciado por: 1) La llegada a Fecode de una nueva generación de dirigentes sindicales.-2) El rompimiento con la izquierda autoritaria. 3) La conquista del Estatuto Do-

\footnotetext{
71 «Socialmente se reconoce como maestro a quien se supone como muy claro, muy sencillo y muy simple para exponer, porque tiene como herramienta fundamental el método. Mientras más desarraigado del saber está el maestro en una formación social y mientras mayor sea su desarraigo cultural, más se enfatiza en su oficio metodológico; de esto último tenemos una muestra muy clara en la forma como existe la Pedagogía, hoy día, en las Facultades de Educación» (Olga Lucía Zuluaga, Pedagogía e Historia, 156).

72 «La práctica sindical de las organizaciones del magisterio no puede continuar reducida al trámite de quejas y reclamos y una agitación en la que sólo participan pequeños grupos de activistas. Se requiere, por consiguiente, trazar un conjunto de tareas y organizar una serie de actividades que sirvan para vincular y comprometer a la gran masa de educadores con los objetivos principales de su movimiento» (Abel Rodríguez, presidente de Fecode, y años más tarde, Secretario de Educación de Bogotá). Abel Rodríguez et al., Veinte años del Movimiento pedagógico (Bogotá: Editorial Magisterio), 34; Alfonso Tamayo, «El Movimiento Pedagógico en Colombia (Un encuentro de los maestros con la Pedagogía)», Revista HISTEDBR On-line, Campinas, 24 (2006): 103.

${ }^{73}$ Revista Educación y Cultura. Fecode- XIII Congreso Nacional- Conclusiones. Bogotá-1985. Citado por Tamayo, «El Movimiento Pedagógico...», 105.
} 
cente. 4) La implantación de la Reforma Curricular. 5) El encuentro del sindicalismo de izquierda con los intelectuales e investigadores de la pedagogía. ${ }^{74}$

El movimiento por el reconocimiento del saber pedagógico «triunfó» cuando se convirtió en política pública en el arriba mencionado reconocimiento oficial de la pedagogía como «la disciplina fundante de la formación de maestros», hasta su posterior derogatoria igualmente burocrática. ${ }^{75}$ Hoy, treinta y tantos años después, habiendo sido replegados los discursos revolucionarios y democratizadores, reemplazados por visiones más pragmáticas, más funcionalistas, más mercantilistas, el régimen de las Ciencias de la Educación no sólo no ha cedido ni un ápice, sino que se ha hecho transnacional a través de las evaluaciones masivas internacionales, la formulación de estándares globales de conocimiento, de nutrición, y de rendimiento para la infancia, y el Estatuto de profesionalización docente 1278 que hemos analizado arriba. Pero tanto investigadores como maestros de base seguimos sosteniendo el poder reconceptualizador y de contra-conducta que puede hallarse en una reconstrucción de la Pedagogía por medio de estos «acoplamientos entre los saberes soterrados de la erudición y los saberes descalificados por la jerarquía del conocimiento y de la ciencia». ${ }^{76}$ De allí emerge bautizada como saber pedagógico, proponiendo su propio campo intelectual y conceptual de pensamiento y de creación, como espacio de composición del sujeto-maestro como sujeto (productor) de saber — sin olvidar sus dimensiones social y política, por el contrario, dándoles nuevos significados-, y definiendo la práctica pedagógica ${ }^{77}$ como ámbito estratégico en la vieja lucha por ese tercer espacio que hoy opone, políticamente, la formación de subjetividades-otras a las fuerzas contemporáneas de la educación estandarizada multinacional y a la privatización de los sistemas nacionales de educación pública.

\footnotetext{
${ }^{74}$ Rodríguez, Veinte años..., 35.

75 Sandra Rodríguez y Alexis Pinilla, «La pedagogía por decreto en la formación de docentes», en comps. O. Pulido y D. Baquero, Formación de maestros, profesión y trabajo docente (Bogotá: UPN-FLAPE, 2005), 164-171.

${ }^{76}$ Michel Foucault, «Curso del 7 de enero de 1976», en La microfísica del poder (Madrid, Editorial La Piqueta, 1980), 125

${ }^{77}$ Zuluaga, Pedagogía e Historia, 196.
} 


\section{Nota sobre los autores:}

Oscar SaldarRiaga Vélez (Duitama, 1957) es historiador. Profesor titular de la Pontificia Universidad Javeriana de Bogotá y doctor en Filosofía y Letras (Historia) de la Universidad católica de Lovaina. Miembro fundador de los Grupos Historia de la práctica pedagógica en Colombia y Saberes, poderes y culturas en Colombia. Es autor de Del oficio de maestro, teorías y prácticas de la pedagogía moderna en Colombia, (Bogotá: Magisterio, 2003), Nova et Vetera: Filosofía neotomista, Educación y Modernidad en Colombia, 1868-1930, (Bogotá: Javeriana, -en prensa-) y coautor de Mirar la Infancia: pedagogía, moral y modernidad en Colombia 1903-1946, (Medellín: U. de Antioquia/UniAndes/ Colciencias/Foro por Colombia,1997). Es también autor de capítulos en obras colectivas como Génesis y desarrollo de los Sistemas Educativos Iberoamericanos siglo XIX; Historia de la Educación en Bogotá; Foucault, la Pedagogía y la Educación; Pensar el Siglo XIX: cultura, biopolítica y modernidad en Colombia; La reestructuración de las ciencias sociales en América Latina; Historia de la infancia en América Latina; Schooling around the World, Actualidad del sujeto; Ensamblado en Colombia; entre otras.

Claudia María Vargas Aldana (Bogotá, 1986) es Licenciada en Ciencias Sociales de la Universidad Pedagógica Nacional y Magistra en Historia de la Pontificia Universidad Javeriana. Ha sido profesora de la Escuela Normal Superior Nuestra Señora de la Paz y de la secretaría de Educación de Bogotá. Tesis de maestría: Trazos de una historia: la configuración del maestro como sujeto político, social y de saber, Bogotá 1945-1957, (Bogotá: Pontificia Universidad Javeriana, 2013). 